\title{
COMPORTAMENTO DE SEMENTES DE ROMÃ (Punica granatum L.) SUBMETIDAS À FERMENTAÇÃO E SECAGEM ${ }^{1}$
}

\author{
KILSON PINHEIRO LOPES ${ }^{2}$, RISELANE DE LUCENA ALCÂNTARA BRUNO³,

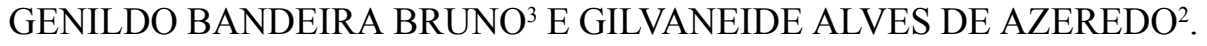

\begin{abstract}
RESUMO - Sementes de romã (Punica granatum L.) foram submetidas a diferentes períodos de fermentação (0; 24; 48; 72 e 96 horas), com e sem secagem. Avaliaram-se suas qualidades física e fisiológica, através das determinações do grau de umidade, peso de 100 sementes, porcentagem de emergência e velocidade de emergência de plântulas (IVE). O delineamento experimental adotado foi inteiramente casualizado, em esquema fatorial, onde os cinco períodos de fermentação frente às duas condições (com e sem secagem) constituíram os tratamentos. Sementes submetidas ao maior período de fermentação apresentaram sarcotestas mais degradadas, favorecendo, conseqüentemente, uma melhor absorção de água, resultando numa porcentagem de emergência de $55 \%$ e IVE de 0,38 , em 72 horas de fermentação. A secagem das sementes após fermentação promoveu uma menor porcentagem de emergência e IVE, apesar de se verificar um aumento de ambos, quando as sementes permaneceram em fermentação por um maior período. $\mathrm{O}$ comportamento verificado nas sementes de romã frente aos tratamentos empregados parece estar associado a fenômenos de dormência ou sensibilidade à secagem, característica esta, de sementes recalcitrantes.
\end{abstract}

Termos para indexação: romã, propagação, tecnologia de sementes.

\section{BEHAVIOR OF POMEGRANATE (Punica granatum L.) SEEDS SUBMITTED THE FERMENTATION AND DRYING}

\begin{abstract}
Pomegranate (Punica granatum L.) seeds were submitted to different fermentation periods (0;24; $48 ; 72$ and 96 hours) and were dried or not, before sowing. It was evaluated the physical and physiological quality of the seeds through the determination of the moisture content, weight of 100 seeds, emergence percentage and speed of seedling emergency. It was used an entirely randomized experimental design $5 \times 2$ (period of fermentation and drying). The seeds submitted to the largest fermentation period, presented the largest percentage of emergence $(55 \%)$ and IVE $(0,38)$. The drying of the seeds after fermentation, promoted the smallest emergency percentage and IVE, in spite of verifying an increase of both, when the seeds stayed in fermentation for a longer period. The behavior verified in the seeds of pomegranate front to the treatment applied seems to be associated to the dormancy phenomenon or sensibility to the drying and they are characteristic of recalcitrant seeds.
\end{abstract}

Index terms: pomegranate, propagation, seeds technology.

\section{INTRODUÇÃO}

A romãzeira (Punica granatum L.), família Punicaceae, tem sido utilizada como planta frutífera, ornamental (parques e jardins) e reúne propriedades medicinais (Correa, 1978). Os seus frutos são originários de ovário ínfero e apresentam pericarpo carnoso-coriáceo; são divididos internamente em muitas lojas e contêm inúmeras sementes irregularmente facetadas, apresentando sarcotesta translúcida, mesotesta esclerótica e testa formada de células polposas (Corrêa, 1978, e Barroso et al., 1999). Segundo Marin et al. (1987), a sarcotesta, por ser um material gelatinoso que envolve a semente, pode vir a comprometer ou não sua germinação, tornando-a lenta e desuniforme. Alguns autores confirmaram tal comportamento, associando-o à possível presença de substâncias inibidoras da germinação (Lange, 1962; Reyes et al., 1980; Schmildt et al.,1993).

A remoção da sarcotesta de sementes da romãzeira pode ser feita por métodos físicos, químicos e mecânicos. Segundo
Dias \& Barros (1993), a fermentação é um processo químico que ocorre de forma natural, por reações de hidrólise, o que facilita a remoção da mucilagem durante a lavagem. Normalmente, este processo consiste na imersão das sementes em água por um período mínimo de 24 horas, seguida de lavagem em água corrente para a eliminação dos resíduos dessa mucilagem.

A secagem, para muitas sementes, é necessária para garantir sua qualidade, no entanto, precisa ser conduzida cuidadosamente, em função dos níveis de umidade que cada espécie exige ou permite; dependendo da forma com que esta operação for realizada, poderá ser prejudicial à manutenção da qualidade da semente ou, mesmo, inutilizá-la totalmente durante o armazenamento (Carvalho \& Nakagawa, 2000).

Com base nessas últimas informações e considerando as peculiaridades das sementes de romãzeira, o presente trabalho foi realizado com o objetivo de avaliar o efeito de diferentes períodos de fermentação e condições de secagem sobre as qualidades física e fisiológica dessas sementes.

1 Trabalho n ${ }^{0}$ 191/2000. Recebido: 01/09/2000. Aceito para publicação: 06/07/2001.

2 Eng $^{\text {os }}$. Agr ${ }^{\text {os }}$. Mestres em Produção Vegetal. Depto. de Fitotecnia - CCA/UFPB. Areia-PB. 58397-000

3 Prof $^{\text {ss }}$. Adjuntos do Depto. de Fitotecnia - CCA/UFPB. Areia-PB. Caixa Postal 22. E-mail: lane@cca.ufpb.br 


\section{MATERIAL E MÉTODOS}

O presente trabalho foi realizado no Laboratório de Análise de Sementes do Departamento de Fitotecnia do CCA/ UFPB, em Areia-Paraíba. Foram utilizadas sementes oriundas de frutos fisiologicamente maduros (pericarpo amarelado com manchas vermelhas), colhidas em um pomar doméstico no município de Serraria-PB, em janeiro de 2000. As sementes, depois de extraídas dos frutos, foram homogeneizadas e, em seguida, separadas em cinco grupos de acordo com os diferentes períodos de fermentação $(0 ; 24 ; 48 ; 72$ e 96 horas) em solução de água destilada e açúcar (10:1). Ao término dos períodos de fermentação, as sementes foram lavadas em água corrente e submetidas ou não à secagem à sombra, em condições de laboratório $\left(32{ }^{\circ} \mathrm{C}\right.$ e $74 \%$ U.R.), durante 9 dias.

As sementes dos diferentes tratamentos foram submetidas à testes visando a avaliar as qualidades física $\mathrm{e}$ fisiológica. A determinação do grau de umidade foi realizada utilizando-se o método da estufa a $105 \pm 3{ }^{\circ} \mathrm{C}$, durante 24 horas (Brasil, 1992), empregando-se duas subamostras de 40 sementes por tratamento; o peso de 100 sementes foi obtido pela pesagem de 5 subamostras de 100 sementes, sendo o resultado expresso pela média aritmética das subamostras. Para o teste de emergência, em condições de casa de vegetação, foram utilizadas quatro subamostras de 25 sementes, sendo essas semeadas em bandejas com dimensões de $45 \mathrm{~cm} \times 30 \mathrm{~cm} \times 7 \mathrm{~cm}$, contendo areia lavada e autoclavada, e a umidade do substrato foi mantida através de irrigações diárias por meio de um regador manual; as avaliações foram realizadas 60 dias após a instalação do teste e o resultado expresso em porcentagem. $\mathrm{O}$ índice de velocidade de emergência (IVE), calculado de acordo com a fórmula proposta por Maguire, citado por Nakagawa (1999), foi baseado na leitura diária do número de plântulas emergidas, a partir do início da emergência ( $28^{\circ}$ dia) até a sua estabilização.

Para análise estatística, o delineamento experimental foi o inteiramente casualizado, em esquema fatorial $5 \times 2$ (cinco períodos de fermentação por duas condições - com e sem secagem), com quatro repetições para cada tratamento; os resultados de emergência e IVE foram submetidos à análise de variância e regressão.

\section{RESULTADOS E DISCUSSÃO}

As sementes de romã não submetidas à secagem (SS) apresentaram os maiores valores de umidade e, conseqüentemente, do peso de 100 sementes (Figura 1). À medida que se aumentou o tempo de fermentação, houve um pequeno acréscimo no grau de umidade das sementes; verificando-se, também, com o período de fermentação, uma redução acentuada do peso com 24 horas de fermentação, mantendo-se aproximadamente igual a partir deste período. Este comportamento evidencia a degradação da sarcotesta, quando as sementes foram submetidas à fermentação por um maior período, expondo o tegumento a uma maior hidratação.

Constatou-se que a porcentagem de emergência e o IVE (Figura 2) das sementes (SS) apresentaram variações com o período de fermentação. Os maiores valores foram encontrados às 72 horas, concomitantemente ao maior conteúdo de água nas sementes (86\%), permitindo deduzir que este aumento está associado à não-paralisação das atividades metabólicas e de absorção de água, resultando na maior quantidade de sementes germinadas. Pelo contrário, a menor porcentagem de emergência ocorreu nas sementes submetidas à secagem. $\mathrm{O}$ fenômeno da germinação, como afirmam Carvalho \& Nakagawa (2000), devese ao aumento da atividade respiratória e demais reações metabólicas, a um nível capaz de sustentar o crescimento do embrião, com fornecimento suficiente de energia e de substâncias orgânicas, por conseqüência, do aumento do grau de hidratação dos tecidos.

Quanto às sementes submetidas à secagem (CS), houve pequena variação no grau de umidade e peso de 100 sementes (Figura 1) ao longo da fermentação (24; 48; 72 e 96 horas), apresentando-se em torno de $12 \% \mathrm{e} 3 \mathrm{~g}$, respectivamente. A perda de umidade verificada naquelas sementes, durante o processo de secagem foi facilitada pelo fato de as mesmas se encontrarem livres da sarcotesta, expondo o tegumento a uma maior desidratação. Acompanhando o comportamento da umidade, estas sementes (CS) apresentaram os menores porcentuais de emergência e valores de IVE (Figura 2), em relação àquelas não submetidas à secagem (SS). De acordo com Bewley \& Black (1982), o grau de umidade é um dos fatores determinantes da dormência em sementes, pois o tegumento das mesmas torna-se progressivamente duro e impermeável à medida que o grau de umidade diminui. No entanto, ao se compararem os resultados de emergência e IVE (Figura 2) com os de umidade (Figura 1), verifica-se que sementes submetidas a um maior período de fermentação e, posteriormente, secas, apesar de mais desidratadas, tenderam a apresentar aumento no vigor. Popinigis (1985) afirmou que, em algumas espécies, a restrição a embebição de água é resultante de modificações causadas pela desidratação das paredes celulares do tegumento da semente. Este autor afirmou, ainda, que estas modificações ocorrem na estrutura micelar das membranas, manifestando-se no potencial de dilatação do gel. Portanto, acredita-se que a permanência das sementes de romã, por um maior período de fermentação, pode ter comprometido a integridade do tegumento, facilitando, com isto, uma melhor reidratação e, por conseqüência, uma mais rápida ativação do processo de germinação.

Sementes submetidas a 24 horas de fermentação, à semelhança daquelas não submetidas (0 hora), apresentaram os menores porcentuais de emergência e valores de IVE, em ambas as condições de secagem. Estas sementes ( 0 hora) foram aquelas que apresentaram as maiores quantidades de sarcotesta, demonstrado pelo grau de umidade e pelo peso de 100 sementes (Figura 1) após secagem. Estes resultados reforçam as afirmações de Marin et al. (1987) quando comentaram que a presença da sarcotesta em sementes pode comprometer a germinação, por apresentarem, possivelmente, substâncias inibidoras.

O comportamento apresentado pelas sementes de romã, no presente trabalho pode também estar associado à sensibilidade à dessecação que algumas espécies apresentam, refletindo nos eventos iniciais do processo de germinação. Segundo Roberts (1973), sementes que não toleram dessecação até níveis abaixo de $12 \%$ a $31 \%$, conforme a espécie, e que não sobrevivem em temperaturas subzero, recebem a denominação de recalcitrantes. Esta tolerância ou não à dessecação é de extrema importância, uma vez que desta depende a conservação de sementes a longo 


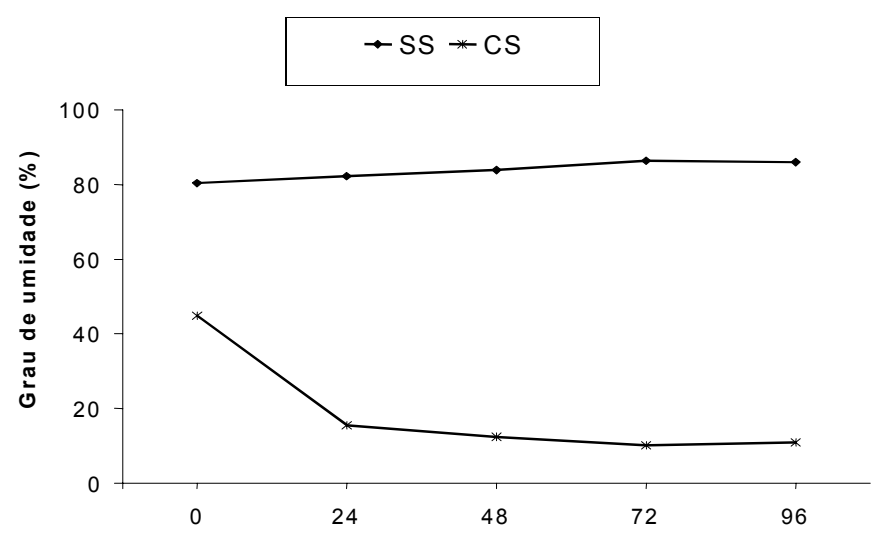

ou a curto prazos. Assim, há necessidade da realização de trabalhos que esclareçam a tolerância ou não, das sementes de romã, à dessecação bem como o comportamento das mesmas frente a outras formas de extração da sarcotesta, com ênfase na eliminação da possível dormência causada pelo tegumento.

\section{CONCLUSÕES}

1. A prática da fermentação foi eficiente na eliminação da sarcotesta em sementes de romã, ocorrendo maior viabilidade e vigor com 72 horas de fermentação.

2. A permanência das sementes em fermentação por um maior tempo promoveu uma maior absorção de água pelas sementes. 3. A secagem das sementes, após os períodos de fermentação promoveu redução da viabilidade e do vigor das sementes.

\section{REFERÊNCIAS BIBLIOGRÁFICAS}

BARROSO, G.M.; MORIM, M.P., PEIXOTO, A.L., ICHASO, C.L.F. Frutos e sementes: morfologia aplicada à sistemática de dicotiledôneas. Viçosa: UFV, 1999. 443p.

BEWLEY, J.D., BLACK, M. Physiology and biochemistry of seeds. Berlin: Springer-verlag, 1982, v.2.

FIGURA 1 - Qualidade física das sementes de romã (Punica granatum L.) submetidas a diferentes tempos de fermentação, com e sem secagem.
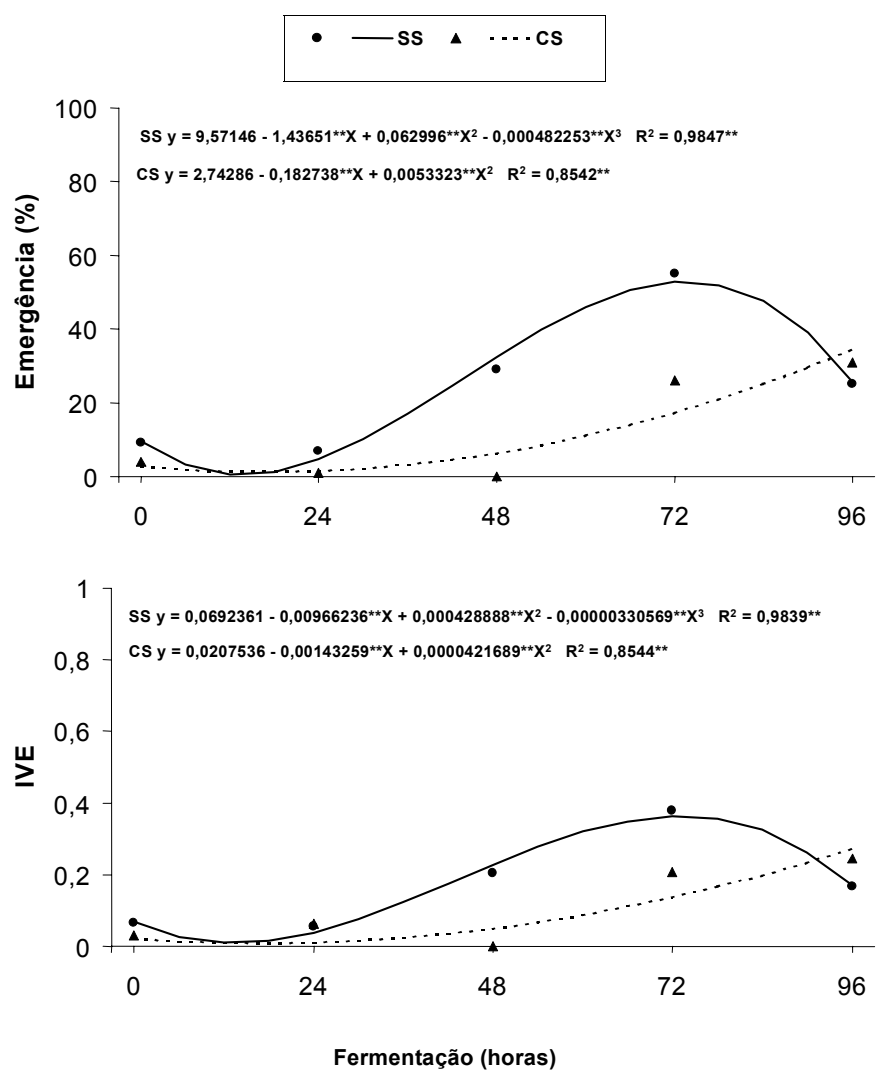

FIGURA 2 - Qualidade fisiológica das sementes de romã (Punica granatum L.) submetidas a diferentes tempos de fermentação, com e sem secagem.

BRASIL, Ministério da Agricultura e Reforma Agrária. Regras para análise de sementes. Brasília: SNDA/DNDV/CLAV, 1992. $365 p$.

CARVALHO, N.M., NAKAGAWA, J. Sementes: ciência tecnologia e produção. 4. ed. Jaboticabal: FUNEP, 2000. 588p.

CORRÊA, P.M. Dicionário das plantas úteis do Brasil e das exóticas cultivadas. Rio de Janeiro: Imprensa Nacional. 1978. v.5, p.609-610.

DIAS, M.C.L. de L.; BARROS, A.S. do R. Avaliação de métodos para remoção da mucilagem de sementes de café (Coffea arabica L.). Revista Brasileira de Sementes, Brasília, v.15, n.2, p.191195, 1993.

LANGE, A.H, Effect of the sarcotesta and sclerotesta on germination of Carica papaya. The Botanical Gazette, Chicago, v.122, n.4, p.305-511, 1962.

MARIN, S.L.D., GOMES, J.A., SALGADO, J.S. Recomendação para a cultura do mamoeiro cv. Solo do Estado do Espírito Santo. 3. ed. Vitória: s.ed., 1987. 64p.

NAKAGAWA, J. Testes de vigor baseados na avaliação das plântulas. In: KRZYZANOWSKI, F.C., VIEIRA, R.D., FRANÇA NETO, J. de B. Vigor de sementes: conceitos e testes. Londrina: ABRATES, 1999. 218p.

POPINIGIS, F. Fisiologia da semente. Brasília: AGIPLAN, 1985. 289p. 
REYES, M.N.; PEREZ, A.; CUEVAS, J. Detecting endogenous growth regulators on the sarcotesta, sclerotesta, endosperm, and embryo by paper chromatography on fresh and old seeds of two papaya varieties. The Journal of Agriculture of the University of Puerto Rico v.62, n.2, p.164-172, 1980.

ROBERTS, E.H. Predicting the storage life of seeds. Seed
Science and Technology, Zürich, v.1, n.1, p.449-514, 1973.

SCHMILDT, E.R.; FRONZA, V.; DIAZ, J.L.S.; UNÊDA, S.H.; ALVARENGA, E.M. Comparação de métodos físicos de remoção da sarcotesta e de métodos de secagem de sementes de mamoeiro (Carica papaya L.). Revista Brasileira de Sementes, Brasília, v.15, n.2, p.147-151, 1993. 